\title{
Formula to Correct Left Ventricular Ejection Fraction in Patients with Mitral Valve Regurgitation
}

\author{
Fórmula para corregir la fracción de expulsión del ventrículo izquierdo en pacientes con \\ insuficiencia valvular mitral
}

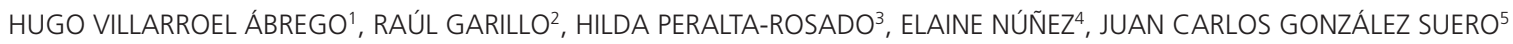

\begin{abstract}
Left ventricular ejection fraction is a key measurement for the assessment of systolic function. In case of mitral valve insufficiency, part of the ejected volume regurgitates to the left atrium, the anterograde volume is less than expected, and the ejection fraction maintains a value that does not adequately represent the inotropic state. This does not allow certain patients with heart failure to be correctly classified and treated, especially regarding the indication of devices (resynchronization therapy and defibrillator implant). Based on the calculation of the regurgitant fraction, we propose a simple formula to make a "correction" of the ejection fraction in this type of cases. The corrected ejection fraction was tested in a group of consecutive outpatients. The study confirmed that $54 \%$ of patients have their prognosis and/or treatment modified when applying the proposed formula.
\end{abstract}

Key words: Ejection fraction - Mitral regurgitation - Regurgitant fraction.

\section{RESUMEN}

La fracción de expulsión del ventrículo izquierdo es una medición clave para la valoración de su función sistólica. En caso de insuficiencia valvular mitral, parte del volumen eyectado se regurgita hacia el atrio izquierdo, el volumen anterógrado es menor que el supuesto y la fracción de expulsión se mantiene en un valor que no representa adecuadamente el estado inotrópico. Esto no permite que ciertos pacientes con falla cardíaca puedan ser correctamente clasificados y tratados, en especial en cuanto se refiere a la indicación de dispositivos (terapia de resincronización, implante de desfibriladores). Tomando como base el cálculo de la fracción regurgitante se propone una sencilla fórmula para hacer una "corrección" de la fracción de expulsión en este tipo de casos y se puso a prueba en un grupo de pacientes ambulatorios citados consecutivamente. Se confirma que en un $54 \%$ de pacientes se ven modificados su pronóstico, su tratamiento o ambos al aplicarse la fórmula propuesta.

Palabras clave: Fracción de expulsión - Insuficiencia mitral - Fracción regurgitante

\section{Abbreviations}

\begin{tabular}{ll|ll} 
AICD & Automatic implantable cardioverter defibrillator & PISA & Proximal isovelocity surface area \\
EROA & Effective regurgitant orifice area & CRT & Cardiac resynchronization therapy \\
LVEF & Left ventricular ejection fraction & SV & Stroke volume \\
CLVEF & "Corrected" ejection fraction & MVSV & Mitral stroke volume \\
LVESV & Left ventricular end-systolic volume & RSV & Regurgitant stroke volume \\
RF & Regurgitant fraction & LVEDV & Left ventricular end-diastolic volume \\
VTI MR & Jet velocity-time integral of mitral regurgitation & &
\end{tabular}

REV ARGENT CARDIOL 2019;87:223-226. http://dx.doi.org/10.7775/rac.v87.i3.15163

Received: 11/30/2018 - Accepted: 02/15/2019

Address for reprints: Dr. Hugo Villarroel-Ábrego. Plaza Villavicencio segundo nivel, San Salvador, El Salvador, Centroamérica - E-mail: h_villarroel@ yahoo.com

${ }^{1}$ Cardiologist, Echocardiography Specialist, School of Medicine, Universidad Salvadoreña "Alberto Masferrer” (USAM),

Hospital de Diagnóstico Escalón, San Salvador, El Salvador.

${ }^{2}$ University Cardiologist. Assistant Professor of Physiology, School of Medical Sciences, Pontificia Universidad Católica Argentina. Buenos Aires, Argentina.

${ }^{3}$ Cardiologist, Echocardiography Specialist, FACC; Clínica de Mérida-Electrodiagnóstico del Sureste y del Hospital General Dr. Agustín O’Horan,

Mérida, Yucatán, Mexico.

${ }^{4}$ Electrophysiologist, Centros de Diagnóstico y Medicina Avanzada y de Conferencias Médicas y Telemedicina (CEDIMAT),

Santo Domingo, Dominican Republic.

${ }^{5}$ Cardiologist, Echocardiography Specialist, Coordinator of the Echocardiography Fellowship, Hospital Regional Universitario Presidente Estrella

Ureña, Santiago de los Caballeros, Dominican Republic. 


\section{INTRODUCTION}

Left ventricular ejection fraction (LVEF) is a commonly used parameter to assess ventricular systolic function, stratify risk and predict survival. (1) Thus, LVEF cutoff values have been established to classify patients with heart failure, $(1,2)$ diagnosis of cardiotoxicity (3) and for decision-making of device implantation: automatic implantable cardioverter defibrillators (AICD) and cardiac resynchronization therapy (CRT). (4) Despite its relevance, LVEF depends markedly on left ventricular preload and afterload conditions (5) and is not a measure of contractility; however, it is a tool usually used due to its easy application in clinical practice.

In mitral valve regurgitation, a fraction of the stroke volume (SV) is returned to the left atrium during ventricular systole. Therefore, the effective SV is lower than that measured from the difference between end-diastolic and end-systolic volumes using the Simpson rule or area-length methods. Because the impedance of the incompetent mitral valve and the left ventricular atrium will always be much lower than that of the aortic valve, a normal LVEF does not accurately reflect the already indirectly assessed left ventricular systolic function, since despite a poor contractile reserve, ventricular backward flow is possible because it goes to a chamber with very inferior pressure, even with severely high atrial filling pressures. Moderate to severe mitral regurgitations, very frequent in patients with heart failure, (6) usually mask a significantly greater pump function impairment (Figure 1). The literature clearly describes how to estimate the regurgitant blood volume to the left atrium in each systole and how to calculate the regurgitant fraction (RF), expressed as percentage. (7-10) It is intuitive to deduct from one (1.0) the value of the $\mathrm{RF}$ in mitral valve insufficiency to know the percent magnitude that should be subtracted from the total ejected volume. If $\mathrm{LVEF}$ is multiplied by this value it would give the corrected or anterograde LVEF. (11) Based on these concepts, the following method using echocardiography has been used to correct LVEF in patients with mitral regurgitation.

\section{METHODS}

To calculate the "corrected" EF (cLVEF) it is necessary to obtain the regurgitant stroke volume (RSV) by the continuity equation or the flow convergence method, measuring the proximal isovelocity surface area (PISA). The latter was the method used in the present study. The calculation requires the effective regurgitant orifice area (EROA) and the jet velocity-time integral of mitral regurgitation (VTI MR). Then:

$$
\mathrm{RSV}=[\mathrm{EROA}(\mathrm{cm} 2) \times \mathrm{VTI} \mathrm{MR}(\mathrm{cm})]
$$

To assess mitral stroke volume (MVSV) it is necessary to calculate the mitral annulus area and the velocity-time integral of the diastolic jet at the mitral annular level (VTI MV):

$\mathrm{MVSV}=\pi$ (mid-diastolic mitral annulus radio) $2 \times \mathrm{VTI}$ MV

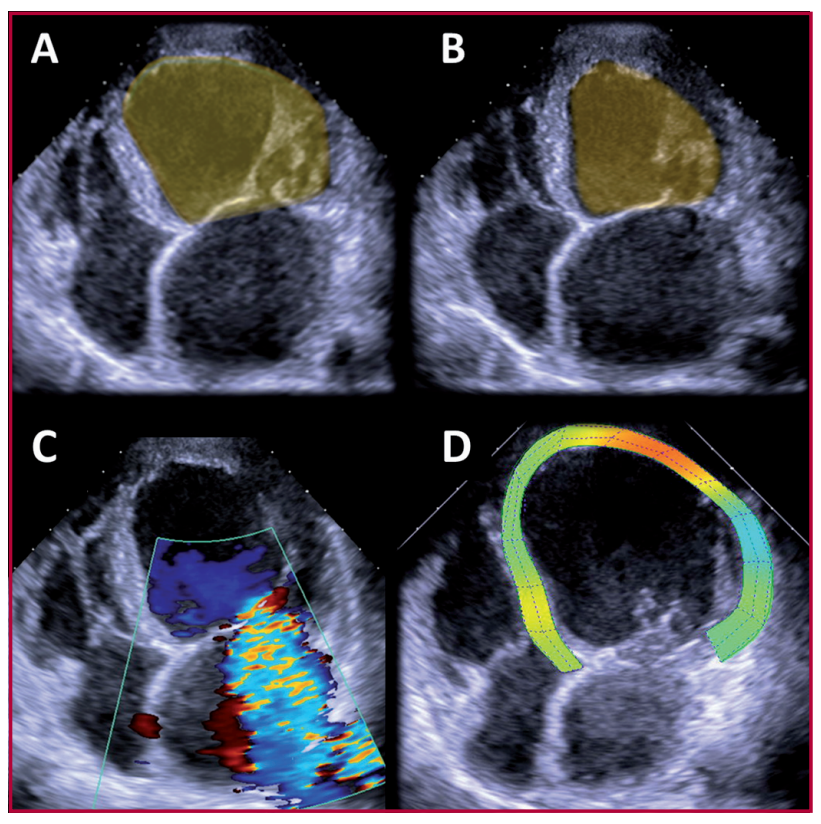

Fig. 2. A. Apical 4-chamber view at end-diastole showing severe dilation of both left heart chambers. B: Apical 4-chamber view at end-systole. C: Mid-systolic jet of moderate to severe mitral regurgitation, with invasion of the pulmonary veins. LVEF: $52 \%$. EROA (effective regurgitant orifice area): $0.32 \mathrm{~cm} 2$, regurgitant fraction: $34.39 \%$. The corrected LVEF drops to $34.1 \%$. A LVEF technically in the "preserved" range masks a severe systolic dysfunction, confirmed with a global longitudinal strain of $-12 \%$ (D).

The regurgitant fraction is thus defined as:

$\mathrm{RF}=\mathrm{RSV} / \mathrm{MVSV}$

Then, LVEF is corrected as:

$\mathrm{cLVEF}=\mathrm{LVEF} \times(1-\mathrm{RF})$.

The aim of the present study was to apply the cLVEF in a series of consecutive patients and confirm that, in certain cases, the adjusted value of LVEF could lead to a change in the diagnostic and even the therapeutic approach:

- that the cLVEF reclassifies the patient in a different category of systolic dysfunction;

that reductions of LVEF below $40 \%$ allow the diagnosis of heart failure with reduced LVEF;

- that LVEF below 35\% (severe systolic dysfunction) indicates therapies not considered until that moment (AICD, CRT, etc.).

\section{Inclusion criteria}

- Sinus rhythm at the time of the echocardiographic study.

- High-quality two-dimensional or three-dimensional images of left ventricular and valvular planes.

- Well-defined pulsed-Doppler recordings of transmitral and transaortic flows in the mitral annular plane and the left ventricular outflow tract, as well as mitral regurgitant jet with continuous Doppler.

- A measurable and symmetric proximal isovelocity hemisphere. 
Exclusion criteria

- Mitral stenosis.

- Rhythm different from sinus rhythm during the echocardiography.

- Aortic regurgitation beyond minimal regurgitation, with vena contracta $>3 \mathrm{~mm}$ or EROA $>0.1 \mathrm{~cm} 2$.

- Intracardiac or extracardiac short circuits (recruitment will only be allowed in case of patent foramen ovale).

- Patients with devices: pacemakers, [AICD or resynchronizers, ventricular assist devices (except in cases in which, with an implanted device, all the echocardiographic data was collected in sinus rhythm, with the pacemaker completely inhibited)].

Acuson SC2000 (Siemens), Vivid 7 (GE Healthcare), Vivid 3 (Pro (GE Healthcare) and Epic 7c (Philips) ultrasound machines were used.

In case of mitral valve regurgitation and once the inclusion criteria are met, the following procedures will be carried out:

Measurement of LVEF according to the procedures fully described in the literature $(9,10)$ using left ventricular enddiastolic and end-systolic volumes (LVEDV and LVESV) and stroke volume (SV). Left ventricular ejection fraction will thus be calculated by the biplane area-length method (from apical 2- and 4-chamber views) or by three-dimensional echocardiography.

The correction of LVEF requires the following data (Figure 2):

- Mitral annular area in mid-diastole in apical 4-chamber projection; VTI MV at the mitral annular level; and PISA of the mitral regurgitation jet.

- Registry of aliasing velocity (Nyquist); measurement of VTI MV and EROA of mitral regurgitation.

- Calculatation of RSV; VMSV and RF.

A total of 52 consecutive ambulatory patients with mitral valve regurgitation, attending the echocardiography laboratory at Villavicencio Plaza (San Salvador, El Salvador) and ISSSTE in Mérida (Yucatán, Mexico) between November 2017 and March 2018 were prospectively included in the study.

\section{Ethical considerations}

All echocardiographic procedures were stored in photography or digital video format, with a minimum of three cycles. All measurements were performed offline and averaged. To use, process and eventually publish the collected information an informed consent was requested from all patients, according to the regulations of the respective Ethics Committees

\section{RESULTS}

Of the 52 patients analyzed, 27 were females (51.9\%) and mean age was $72.5 \pm 15.8$ years (range: $35-99$ years). A total of 25 patients $(49.1 \%)$ had uncorrected $\mathrm{LVEF} \geq 53 \%$, considered as normal; the remaining 27 patients presented subnormal uncorrected LVEF, and among them, 14 had LVEF <35\% (26.9\%). The PISA method could not be employed in only three patients (5\%-8\%) due to technical limitations, so in these cases, the method based on the continuity equation was used. Mild mitral regurgitation was found in $57.7 \%$ of cases (EROA <0,3 cm2 and $\mathrm{RF}<30 \%, \mathrm{n}=32$ ) and severe regurgitation was detected in 8 patients $(15.4 \%)$.

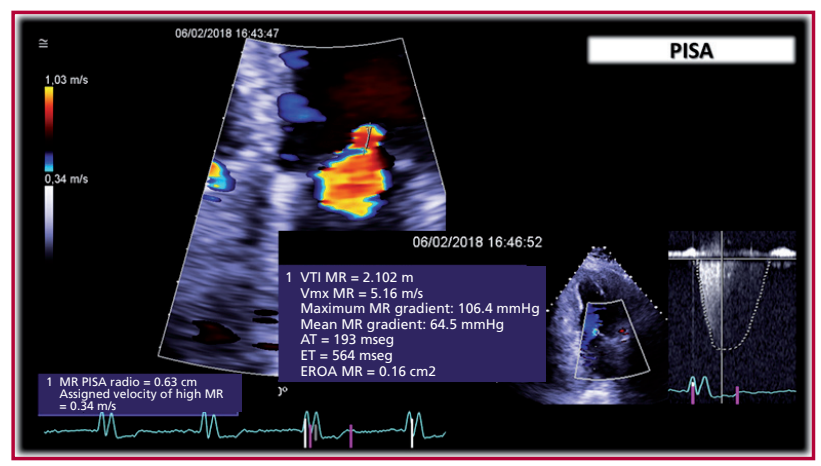

Fig. 2. Measurements for the calculation of the regurgitant fraction in mitral insufficiency by the PISA method. MR: Mitral regurgitation. VTI MR: Velocity-time integral of mitral regurgitation. AT: Acceleration time. ET: Ejective time. EROA MR: Effective regurgitant orifice area of mitral regurgitation. See more explanations in the text.

In 28 patients $(54 \%)$ the result of $\mathrm{LVEF}$ correction led to a change in the clinical classification or treatment perspective (Figure 3); this occurred even in cases of mild mitral regurgitation (17 cases, $32.7 \%$ ). New cases of mild ventricular dysfunction (LVEF $40 \%$ $52.99 \%$ ) were $13=25 \%$ of patients; new cases of heart failure with reduced LVEF $(<40 \%)$ were $12=23.1 \%$ of patients and new cases of heart failure with severe systolic dysfunction (LVEF <35\%), a subgroup of the previous category) were $11=21.1 \%$ of patients.

\section{DISCUSSION}

Left ventricular ejection fraction may be normal even in patients with important myocardial damage, and this has encouraged the search of more sensitive contractility markers, as strain echocardiography. A daily example of this practice is the evaluation of patients with anticancer chemotherapy, (3) in whom the LVEF declines only in advanced myocardial injury. Discordance between LVEF and strain values have already been reported in the same patient, in the same study. One of the possible explanations for this mismatch could be the presence of ischemia, chronic left ventricular pressure or volume overload, or significant mitral valve regurgitation. (12)

A careful review of the literature has shown some reports suggesting solutions to adjust the LVEF value in the presence of mitral regurgitation. $(11,13,14)$ Our group has generated a simple and operative formula that summarizes and simplifies these proposals.

\section{CONCLUSIONS}

An important percentage of consecutive patients with mitral regurgitation has cLVEF that reclassifies them in different categories of previously undiagnosed systolic dysfunction and heart failure. The following recommendations are postulated:

In case of mild ventricular dysfunction, even mild degrees of mitral regurgitation can reclassify the patients. 


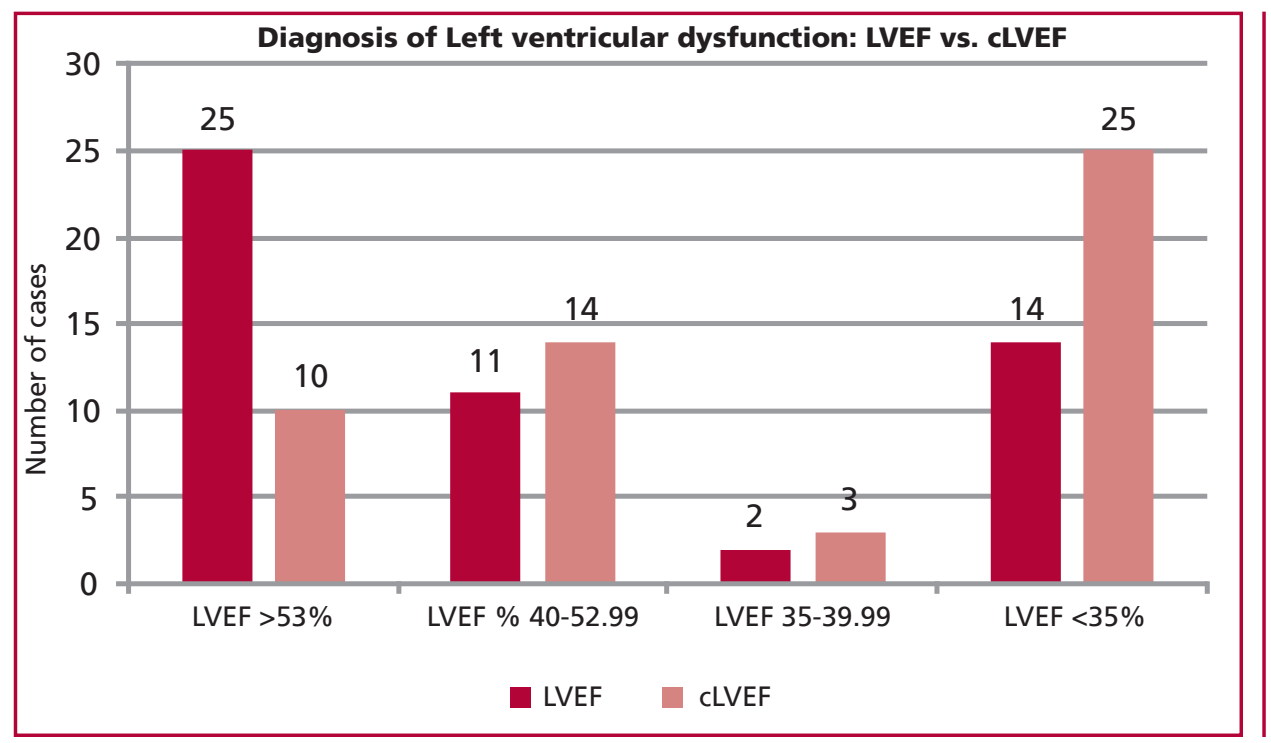

Fig. 3. Changes in the distribution of patients according to the corrected LVEF after applying the described formula.

Moderate mitral regurgitation ( $\mathrm{RF}>30 \%$ ) should be a criterion to correct LVEF in all cases, anticipating a very significant reduction of LVEF.

The formula should be incorporated to automatic calculation packages of the different ultrasound machine brands, to avoid offline calculations.

\section{Conflicts of interest}

Dr Raúl Garillo is Education and Training Consultant of Medtronic Latin America

The rest of the authors have no conflicts of interest.

(See authors' conflicts of interest forms on the website Supplementary material).

\section{REFERENCES}

1. Bui AL, Horwich TB, Fonarow GC. Epidemiology and risk profile of heart failure. Nat Rev Cardiol 2011;8:30-41. http://doi.org/bwnx4v. 2. Paulus WJ, van Ballegoij JJ. Treatment of Heart Failure with Normal Ejection Fraction. An Inconvenient Truth! J Am Coll Cardiol 2010;55:526-37. http://doi.org/ddhv6z.

3. Yu AF, Ky B. Roadmap for biomarkers of cancer therapy cardiotoxicity. Heart. 2016;102:425-30. http://doi.org/f8bzd5.

4. Ponikowski P, Voors AA, Anker SD, Bueno H, Cleland JGF, Coats AJS, et al; ESC Scientific Document Group. 2016 ESC Guidelines for the diagnosis and treatment of acute and chronic heart failure: The Task Force for the diagnosis and treatment of acute and chronic heart failure of the European Society of Cardiology (ESC) Developed with the special contribution of the Heart Failure Association (HFA) of the ESC. Eur Heart J 2016;37:2129-200. http://doi.org/gbv2k3.

5. Mérillon JP, Ennezat PV, Guiomard A, Masquet-Gourgone C, Aumontd MC, Gourgoneet R. Left ventricular performance is closely related to the physical properties of the arterial system: Landmark clinical investigations in the 1970s and 1980s. Arch Cardiovasc Dis 2014;107:554-62. http://doi.org/f6s69n.

6. Varadarajan P, Sharma S, Heywood T, Pai RG. High prevalence of Clinically Silent Severe Mitral Regurgitation in Patients with Heart Failure: Role for Echocardiography. J Am Soc Echocardiogr 2006;19:1458-61. http://doi.org/dhdhxb.

7. Lang RM, Bierig M, Devereux RB, Flachskampf FA, Foster E, Pellikka P, et al. Recomendaciones para la Cuantificación de las Cavidades: Informe del Comité de Guías y Estándares de la Sociedad Americana de Ecocardiografía y del Grupo Redactor de la Cuantificación de las Cavidades, desarrollado conjuntamente con la Asociación Europea de Ecocardiografía, rama de la Sociedad Europea de Cardiología. J Am Soc Echocardiogr 2005;18:1440-63. http://doi. org $/ \mathrm{b} 92 \mathrm{~m} 9 \mathrm{w}$.

8. García-Fernández MA, Gómez de Diego JJ. Cuantificación en Ecocardiografía. Momento Médico, Srl. Salerno, Italia, 2011.

9. Asgar AW, Mack MJ, Stone GW. Secondary Mitral Regurgitation in Heart Failure Pathophysiology, Prognosis and Therapeutic Considerations. J Am Coll Cardiol 2015;65:1231-48. http://doi.org/b9h9. 10. Zoghbi WA, Adams D, Bonow RO Enriquez-Sarano M, Foster E, Grayburn PA, et al. Recommendations for Noninvasive Evaluation of Native Valvular Regurgitation: A Report from the American Society of Echocardiography Developed in Collaboration with the Society for Cardiovascular Magnetic Resonance. J Am Soc Echocardiogr 2017;30:303-71.

11. Enciso R, Summerson C, Aguilar JA Badui E, Lepe L. Cuantificación de la insuficiencia mitral con el método del flujo convergente proximal por eco Doppler-color. Rev Mex Cardiol 1997;8:52-60.

12. Gaasch WH, Meyer TE. Left ventricular response to mitral regurgitation. Circulation 2008;118:2298-303. http://doi.org/ckqh9j.

13. Villarroel-Ábrego H, Garillo R, González-Suero JC, Nuñez Ayala E. Correlación entre fracción expulsiva del ventrículo izquierdo y strain longitudinal global en pacientes con hipertensión arterial. Insuf Card 2018;13:57-6.

14. Abd-El-Aziz TA, Abd-El-Fatah HF, Khalil TS, Mansour KS, AbdEl-Hamid AF, Abd-El-Barry KH. Study of the value of Corrected Ejection Fraction in the Evaluation of Left ventricular Function in Patients with Mitral or Aortic Regurgitation. Angiology 51:555-64. http://doi.org/b3ff54.

15. Witkowski TG, Thomas JD, Delgado V, van Rijnsoever E, Ng ACT, Hoke U et al. Changes in Left Ventricular Function After Mitral Valve Repair for Severe Organic Mitral Regurgitation. Ann Thorac Surg 2012; 93:754-60. http://doi.org/fzgw9d. 